\title{
Pulmonary nodules as incidental findings
}

\author{
Michael Simon MD, Katherine Zukotynski MD, David M. Naeger MD
}

Cite as: CMAJ 2018 February 12;190:E167. doi: 10.1503/cmaj.171223

1 Pulmonary nodules are common incidental findings on imaging About $30 \%$ of all chest computed tomography (CT) scans contain one or more pulmonary nodules. ${ }^{1}$ Larger nodules can also be seen on chest radiographs. ${ }^{2}$

\section{2}

\section{Most pulmonary nodules are benign}

The most common cause of a pulmonary nodule is a previous infection. Other benign entities include active infection and hamartomas. ${ }^{2}$ Malignant disease (both primary and metastatic) is less common, although it is the possibility of malignant disease that drives the need for follow-up. Even in smokers - those at highest risk for lung cancer - nodules are usually benign; in the National Lung Screening Trial, $96 \%$ of all nodules (and $93 \%$ of nodules $\geq 6 \mathrm{~mm}$ ) were benign. ${ }^{3}$

\section{Patient and nodule risk factors are important for determining} the next step

The recently updated Fleischner Society guideline for management of incidental pulmonary nodules recommends assessing patient risk factors, such as smoking history, exposures and family history, as well as nodule risk factors, such as size, density, multiplicity, morphology and growth. ${ }^{4}$

\section{4}

\section{Not all nodules require routine follow-up}

Nodules smaller than $6 \mathrm{~mm}$ do not need to be routinely followed up, given that such nodules have been determined to be very low risk. In those nodules that require follow-up, chest $\mathrm{CT}$ is usually recommended between 3 and 12 months. ${ }^{4}$ In patients who meet guideline criteria for lung cancer screening, recommendations for follow-up are typically based on the Lung CT Screening Reporting and Data system (Lung-RADS), which is tailored to, and validated in, screening populations (www.acr.org/Clinical -Resources/Reporting-and-Data-Systems/Lung-Rads).

\section{5}

\section{Chest CT is useful for following pulmonary nodules ${ }^{4}$}

Chest CT can detect a 1-2 mm change in pulmonary nodule size and can be performed with a noncontrast, low-radiation exposure technique. ${ }^{2}$ Positron emission tomography/CT is sometimes used to evaluate larger, higher-risk pulmonary nodules. ${ }^{5}$

\section{References}

1. Gould MK, Tang T, Liu IL, et al. Recent trends in the identification of incidental pulmonary nodules. Am J Respir Crit Care Med 2015 192:1208-14.

2. Sim YT, Poon FW. Imaging of solitary pulmonary nodule: a clinical review. Quant Imaging Med Surg 2013;3:316-26.

3. Aberle DR, Adams AM, Berg CD, et al.; National Lung Screening Trial Research Team. Reduced lung-cancer mortality with lowdose computed tomographic screening. N Engl J Med 2011;365: 395-409.

4. MacMahon H, Naidich DP, Goo JM, et al. Guidelines for management of incidental pulmonary nodules detected on CT images: from the Fleischner Society 2017. Radiology 2017;284:228-43.

5. Mosmann MP, Borba MA, de Macedo FP, et al. Solitary pulmonary nodule and (18)F-FDG PET/CT. Part 2: accuracy, costeffectiveness and current recommendations. Radiol Bras 2016; 49:104-11.

\section{Competing interests: None declared.}

This article has been peer reviewed.

Affiliations: Department of Medicine (Simon), Maimonides Medical Center, Brooklyn, NY; McMaster University (Zukotynski), Hamilton, Ont.; Department of Radiology \& Biomedical Imaging (Naeger), University of California, San Francisco, Calif.

Correspondence to: David Naeger, David.Naeger@ucsf.edu

CMAJ invites submissions to "Five things to know about ..." Submit manuscripts online at http://mc. manuscriptcentral.com/cmaj 